\title{
ANALYZING THE RAINFALL AND TEMPERATURE INFLUENCE ON MUNICIPAL WATER CONSUMPTION USING REGRESSION TECHNIQUE
}

\author{
Surendra H J $\mathbf{J}^{1}$, Ganesh $\mathbf{S} \mathbf{P}^{2}$, Pruthvi Raj $\mathbf{V}^{3}$, Paresh Chandra Deka ${ }^{4}$ \\ ${ }^{I}$ Research Scholar (NITK) \& Asst. Professor Civil Department, REVA ITM, Karnataka, India \\ ${ }^{2} U G$ Student, Civil Department, REVA ITM, Karnataka, India \\ ${ }^{3} U G$ Students, Civil Department, REVA ITM, Karnataka, India \\ ${ }^{4}$ Associate Professor, Applied Mechanics \& Hydraulics, NITK Surathkal, Karnataka, India
}

\begin{abstract}
Water is known as an important resource. Many factors influencing the water consumption, identifying the factors influencing the water consumption is an active area of research work. This research aims at studying the relationship among the climatic variables such as rainfall and temperature \& its influence on water consumption using regression technique. For this purpose rainfall, maximum and minimum temperature and water consumption data were collected on monthly basis and it is divided into two parts training and testing. Model performance is evaluated using correlation coefficient (CC), Prediction error (PE), Root mean square error (RMSE) and Accuracy. From the result it is cleared that regression technique can be used effetely for the prediction purpose and rainfall and temperature variables is influences the water consumption.
\end{abstract}

Keywords: Rainfall, Temperature, Water consumption, Regression technique

\section{INTRODUCTION}

Climatic behavior prediction is one of the challenging tasks to meteorological society all over the world. Its variability is directly influence on many sectors such as agriculture, water etc. So it is necessary to determine the relationship among the climatic variables and its influence on these sectors. In this research work, influence of climatic variables such as rainfall, maximum and minimum temperature on water consumption in an urban area is analyzed using regression technique. [6] examined climatic variability of the city using multivariate analysis, result indicate that annual water use is controlled most by the overall state of drought, autumn temperature and summer monsoon precipitation. [3] Analyzed daily water use in a water distribution zone by using simple time series approach. Here they have shown how threshold level of temperature and rainfall were identified. [4] Describes and compared a series of predictive model for forecasting hourly water demand. [7] Explores the strategies to improve water management by tracking, anticipating and respond to seasonal to interannual climatic variability and climatic change. [5] Investigated the influence of seasonal and explanatory variables on water consumption. [1] Investigated the complex understanding of how temperature affects water use pattern. Geographical information system and statistical analysis is used to compare the spatial relationship among single family residential water use pattern, water use characteristics and temperature. [2] Forecasted the water consumption using multiple linear regression model using variables such as population served, monthly mean temperature and monthly total precipitation. [8] Investigates whether there is a statistically significant impact of short term climate variables (especially air temperature and rainfall) on residential water consumption at two selected case sites in the Czech Republic using daily time series data.

\subsection{Study Area}

The present study area covers the Yelahanka city located at 13006 '30" to 77034'15" which is a suburb of Bangalore in the state of Karnataka. It is located near the fast developing northern section of Greater Bangalore, about 14 kilometers from downtown Bangalore. State Highway 9, BangaloreHindupur passes through Yelahanka bisecting the suburb into Old Town and New Town. Yelahanka is at a height of about $915 \mathrm{~m}$ above mean sea level. Due to its higher altitude from mean sea level, it is lush green and has pleasant weather year round. The summer season lasts from March to mid-May, with a temperature in the range 200-350. At the end of May, the monsoon season starts and lasts until the end of October. There are about $1143 \mathrm{~mm}$ of rainfall annually. Yelahanka is served by both South west as well as South east monsoon. Winters are mild and last from November to February, with a temperature in the range 140-240. Variation of rainfall is represented in the figure 1 . Seasonal variations of rainfall for last two years is compared \& represented in the figure 2 . 
Similarly variation of monthly maximum and minimum temperature and water consumption is represented in the

figure 3 and 4 respectively

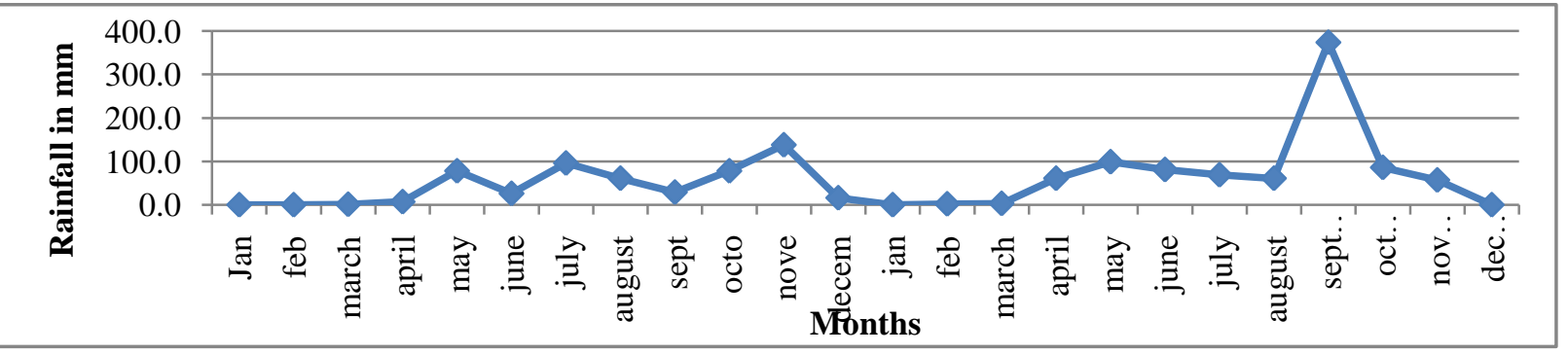

Fig1: Time series plot of monthly rainfall

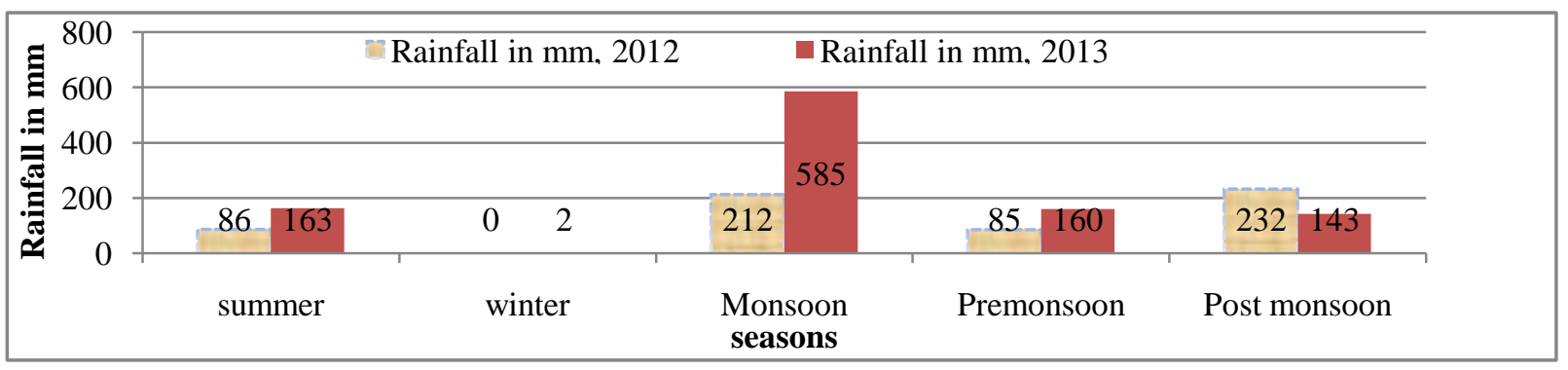

Fig 2: Time series plot of seasonal rainfall of last two years

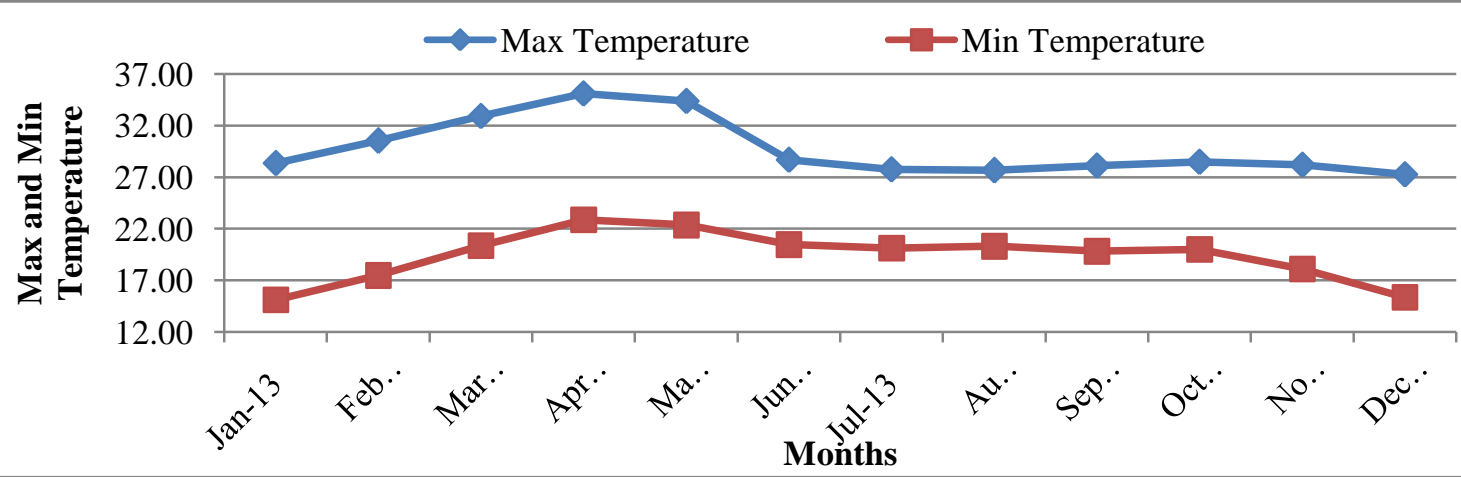

Fig 3: Time series plot of monthly maximum and minimum temperature

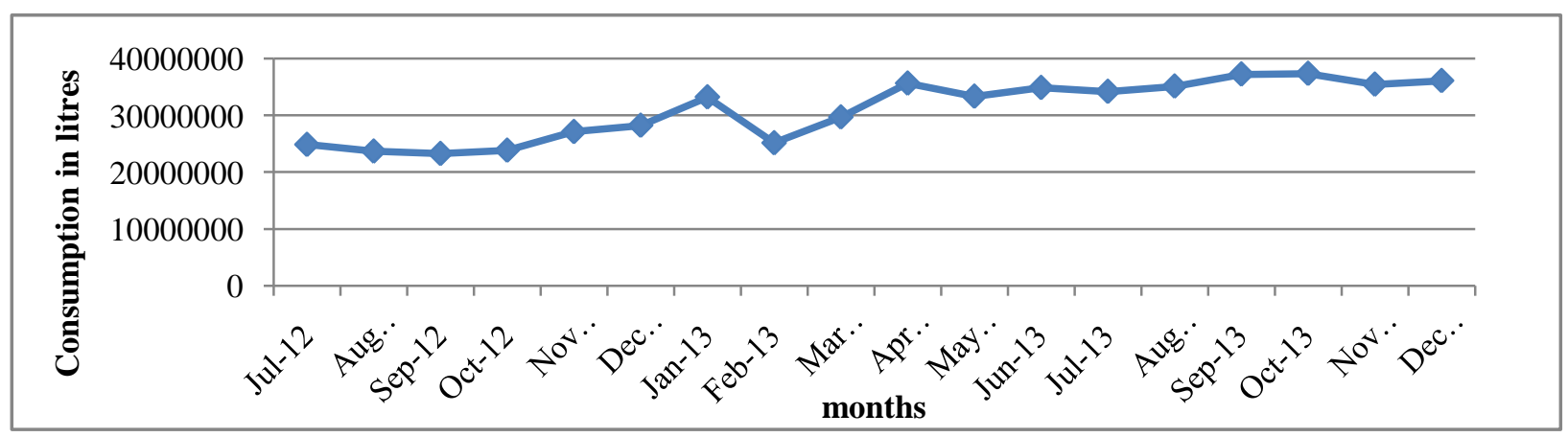

Fig 4: Time series plot of monthly water consumption 


\subsection{Model Development and Methodology}

Identifying the appropriate input variables which influence water consumption, determines the model structure and also plays important role in the model results Hence input variable is selected based on the correlation coefficient (CC). $\mathrm{CC}$ value of all the variables were represented in the table1. For the analysis purpose water consumption, rainfall, maximum and minimum temperature data is collected on monthly basis and it is divided into training and testing part. Statistical properties of the data set are represented in the table 2 .

Table-1: correlation coefficient of all the variables

\begin{tabular}{|l|l|l|l|l|}
\hline Correlation coefficient & Rain Fall & Min temperature & Max Temperature & Water Consumption \\
\hline Rain Fall & 1.000 & 0.270 & -0.122 & 0.265 \\
\hline Min temperature & 0.270 & 1.000 & 0.624 & 0.128 \\
\hline Max Temperature & -0.122 & 0.624 & 1.000 & 0.019 \\
\hline Water Consumption & 0.265 & 0.128 & 0.019 & 1.000 \\
\hline
\end{tabular}

Table-2: statistical properties of all the variables

\begin{tabular}{|l|l|l|l|l|l|l|}
\hline variables & Maximum & minimum & Mean & S.D & C.V & skewness \\
\hline Rainfall & 374.0 & 0.0 & 72.8 & 84.9832 & 1.1668 & 2.7905 \\
\hline Min temperature & 22.9 & 15.1 & 19.2 & 2.2081 & 0.1153 & -0.3480 \\
\hline Max temperature & 35.1 & 27.3 & 29.4 & 2.3710 & 0.0808 & 1.6399 \\
\hline Water consumption & 373849382 & 232793397 & 310426447 & 52092549.6884 & 0.1678 & -0.3564 \\
\hline
\end{tabular}

\subsection{Regression Method}

In this research work regression model developed is in the following form;

$$
Y=\beta_{0}+\beta_{1} x_{1}+\beta_{2} x_{2}+\beta_{3} x_{3}
$$

This is the multiple regression equation with three independent variables and one dependent variable $\mathrm{Y}$. where $\mathrm{Y}$ is the target strength. Here linear regression used because equation is linear function of the unknown parameter $\beta 0, \beta_{1}, \beta_{2}, \beta_{3} \&$ hence it is called as partial regression coefficient.

\subsection{Performance Evaluation}

\subsubsection{Correlation Coefficient (CC)}

It is measure of the strength of the linear relationship between two variables. It is defined in terms of the covariance of the variables divided by their standard deviations.

$$
C C=\frac{\sum\left(x-x^{\prime}\right)\left(y-y^{\prime}\right)}{\sqrt{\left(x-x^{\prime}\right)\left(y-y^{\prime}\right)^{2}}}
$$

\subsubsection{Root Mean Square Error (RMSE)}

It is used to measure the prediction accuracy between the predicted model and actually observed model.

$$
\operatorname{RMSE}=\sqrt{(\mathrm{x}-\mathrm{y})^{2}} / \mathrm{N}
$$

\subsubsection{Prediction Error}

$$
P E=\left[\frac{Y-X}{X}\right)
$$

If the PE value is close to 0 , then the model is treated as best one.

\subsubsection{Accuracy}

$$
100 \text { - RMSE }
$$

Where,

$\mathrm{N}=$ the number of data pattern in the independent data set.

$\mathrm{x}=$ the observed values

$\mathrm{y}=$ the predicted values

$\mathrm{x}^{\prime}=$ Mean of the observed values.

$\mathrm{y}^{\prime}=$ Mean of the predicted values

\section{RESULTS AND DISCUSSION}

Table 3, shows the results of regression technique. Due to limitation of the data set, only few years of data is used for analysis purpose. Due to that there is an error obtained which shows that predicted value is deviated from the observed values. The result shows that accuracy obtained almost near to $76 \%$ and prediction error is negative because observed water consumption value is more compared to the predicted one. Correlation coefficient of the predicted model is 0.692, which shows that the result is fairly good. From the overall 
performance we can say regression model is capable for the prediction purpose, also rainfall and temperature influences the water consumption.

Table 3: Results of all the performance evaluation

\begin{tabular}{|l|l|l|l|}
\hline \multicolumn{3}{|l|}{ Regression Technique } \\
\hline CC & $\begin{array}{l}\text { Prediction } \\
\text { Error }\end{array}$ & RMSE & $\begin{array}{l}\text { Accuracy } \\
(\%)\end{array}$ \\
\hline 0.692 & -0.258 & 21.50 & 76.18 \\
\hline
\end{tabular}

\section{CONCLUSIONS}

In this work an attempt is made to find out the influence of rainfall and temperature on municipal water consumption using regression technique. Due to limitations of the data set, only two years of data were used for the analysis. Since some other parameters influences the water consumption \& data also less, obtained accuracy is less. But From the performance evaluation obtained accuracy is fairly good and it can be acceptable; hence it can be used efficiently for prediction purpose.

\section{FUTURE WORK}

Accuracy of the model can be improved by using some more variables influencing the water consumption with large no of years of data set. Also advance soft computing techniques such as fuzzy logic, neural network, adaptive neural fuzzy inference system, wavelet transformer can be used to improve the accuracy of the model etc.

\section{ACKNOWLEDGEMENTS}

Authors are thankful to Disaster management cell, yelahanka, Bangalore and BWSSB for providing climatic as well as water consumption data. Also a special thanks to all the faculty members of the civil department and principal Dr.R.P.Reddy sir for his continuous support to all the work.

\section{REFERENCES}

[1] Breyer B., Chang H., Parandvash H (2012). "Land use, temperature and single -family residential water patterns in Portland, Oregon and Phoenix, Arizona". Journal of Applied geography 35(2012)142-151.

[2] Birge O., Ali yurdusev M., Turan M (2013). "Urban water demand forecasting based on climatic change scenarios". 2nd International conference on challenge of civil Engineering, BCCCE, 23-25, amy 2013, Epoka University, Tiruna, Albania.

[3] Gato, S., Jayasuriya, N., Roberts, peter., 2007. Temperature and rainfall thresholds for base urban water demand modeling. Journal of hydrology 337(2007): 364-376.
[4] Herrera, M., Torgo, L., Izquierdo, J., Garcia, R., 2010. Predictive models for forecasting hourly urban water demand. Journal of hydrology 387 (2010): 141-150.

[5] Kossay K (2011). "Calculating and modeling of indoor water consumption factor in Mosal city, Iraq". Journal of Environmental studies, Vol. 6, pp: 39-52.

[6] Robert. C., Balling Jr., Patricia Gober (2006). "Climatic Variability and Residential water use in the city of Phoenix, Arizona". Journal of Applied Meteorology and Climatology, Vol.46, pp; 1130-1136.

[7] Sharma K.D., Gosain A.K (2010). "Application of climatic Information and predictions in water sector: Capabilities". Journal of Environmental sciences, Vol.1, pp: 120-129.

[8] Slavikova . L., Maly V., Rost M., Petruzela L., Vojacek O (2013)." Impacts of Climatic Variables on Residential Water Consumption in the Czech Republic". Water Resource Manage, Vol.27, 365-379. 